EXTENDED REPORT

\title{
Do steroids increase lymphoma risk? A case-control study of lymphoma risk in polymyalgia rheumatica/ giant cell arteritis
}

\author{
J Askling, L Klareskog, H Hjalgrim, E Baecklund, M Björkholm, A Ekbom
}

Ann Rheum Dis 2005;64:1765-1768. doi: 10.1136/ard.2005.036459

See end of article for authors' affiliations

Correspondence to:

Correspondence to:
Dr Johan Askling, Clinical Epidemiology Unit M9:01, Department of Medicine, Karolinska University Hospital Solna, SE-171 77 Stockholm, Sweden. johan.askling@medks.ki.se

Accepted 14 April 2005 Published Online First 20 April 2005

\begin{abstract}
Background: Recent studies indicate increased risks of malignant lymphomas among individuals treated with corticosteroids, but have not taken into account the underlying reasons for steroid use, so the increased risks might be attributable to the underlying disease or concomitant treatments other than steroids. Polymyalgia rheumatica (PMR) and temporal arteritis (giant cell arteritis, GCA) are common inflammatory conditions treated with steroids as single immunosuppressive therapy, but data on lymphoma risk in GCA/PMR are limited.

Objective: To assess the risk of lymphoma associated with steroid treatment of GCA/PMR.

Methods: The association between GCA/PMR and malignant lymphomas (overall, and separately for non-Hodgkin lymphoma, Hodgkin lymphoma, and chronic lymphatic leukaemia) was examined in a nationwide, population based, case-control study of 42676 lymphoma cases and 78487 matched population controls, using prospectively recorded data on lymphomas from the Swedish cancer register 1964-2000 and data on pre-lymphoma hospital admissions for GCA/PMR from the Swedish inpatient register 1964-2000. Odds ratios (OR) associated with a pre-lymphoma hospital admission for GCA/PMR were calculated using conditional logistic regression.

Results: 153 lymphoma cases and 345 population controls had a history of GCA/PMR, resulting in an overall OR for malignant lymphomas of 0.81 (95\% confidence interval, 0.67 to 0.98 ). The OR varied little with lymphoma type, sex, age, and calendar period. The OR for GCA was 0.67 (0.48 to 0.98 ) and for PMR, 0.83 (0.67 to 1.04).

Conclusions: Treated GCA is not associated with increased lymphoma risks, which suggests that even at considerable cumulative doses, steroids may not appreciably increase lymphoma risk.
\end{abstract}

$\mathrm{B}$ ecause of their pronounced anti-inflammatory properties, glucocorticoids ("steroids") belong to the most widely used drugs worldwide. Consequently, reports of their putative malignant side effects have public health implications and warrant serious attention. It is therefore of concern that a clear majority ${ }^{1-4}$ of all case-control studies ${ }^{1-6}$ that have included an assessment of the association between steroids and risk of malignant lymphomas, and a recent cohort study using a population based prescription database, have reported that steroid use is accompanied by increased lymphoma risks, with doubled risks in individuals reporting "long" duration of steroid treatment (more than two months, ${ }^{2}$ more than 10 prescriptions, ${ }^{7}$ or not defined ${ }^{3}$ ). Common to all above studies, however, is the inability to take into account the conditions necessitating steroid treatment. Steroids are often used in the treatment of autoimmune or inflammatory conditions, many of which carry an increased lymphoma risk per se or through treatment with other potentially lymphoma inducing immunosuppressive drugs. ${ }^{8-15}$ This methodological problem is not trivial, and may even account for the observed doseresponse-like association between steroids and lymphoma risk. ${ }^{4}$ Along with limited power and little information on treatments beyond a few months, such uncontrolled confounding by indication therefore hampers the interpretation of past studies. One way to reduce bias resulting from confounding by indication of an undefined array of underlying conditions and concomitant treatments is to assess the lymphoma risk in patients with a single medical condition, for which steroids have been the single therapy in homogeneous and clinically relevant dosages, and in which the duration of daily steroid use exceeds a few months.
Because of the dramatic effects of steroids in polymyalgia rheumatica (PMR) and giant cell arteritis (GCA), oral steroids-typically between 10 and $100 \mathrm{mg}$ of prednisone daily tapered over one to two years-have long been the approved treatment of choice, with close to $100 \%$ of diagnosed individuals put on steroids as single immunosuppressive therapy. ${ }^{16}$ Cumulative doses above $10 \mathrm{~g}$ are not infrequent. Treatment with other immune suppressants is less effective and rare. ${ }^{16}{ }^{18}$ GCA/PMR thus constitutes a near ideal proxy marker for considerable exposure to oral steroids in the absence of long standing inflammation of varying degree, as seen in, for example, rheumatoid arthritis, and in the absence of other immunosuppressive drugs. To assess the risk for lymphoma associated with steroids, we therefore undertook a population based nationwide case-control study of malignant lymphomas in relation to a history of GCA/ PMR, taking advantage of the high quality Swedish health and census registers.

\section{METHODS}

\section{Cases and controls}

In the Swedish Cancer Register (with nationwide and nearly complete coverage ${ }^{1920}$ ) we identified as cases all individuals 50 years or older who were registered with a diagnosis of Hodgkin's lymphoma (HL), non-Hodgkin's lymphoma (NHL), or chronic lymphatic leukaemia (CLL) between 1964 and 1999, including information on dates of birth and

Abbreviations: CLL, chronic lymphatic leukaemia; GCA, giant cell (temporal) arteritis; HL, Hodgkin lymphoma; NHL, non-Hodgkin lymphoma; NSAID, non-steroidal anti-inflammatory drug; PMR, polymyalgia rheumatica 
diagnosis of lymphoma, and sex. In the nationwide population register (the Swedish census register), two controls for each case were identified, matched on sex, year of birth, marital status (unmarried, married, widow), and county of residence at the year of lymphoma diagnosis in the case. After exclusion of cases and controls born outside Sweden, and of controls themselves diagnosed with lymphoma before their case, 42676 cases and 78487 controls remained (table 1). Through linkage with the register of total population, we also identified registered spouses of cases and controls up to the time of the diagnosis of lymphoma in the case.

\section{Polymyalgia rheumatica/giant cell arteritis}

Swedish inpatient care is public and population based. Referrals to hospital are based on geography rather than insurance or financial capacity. The Swedish Inpatient Register contains population based and individual information on inpatient care. Starting in 1964, the coverage encompassed $50 \%$ of all counties in the mid 1970s, and $100 \%$ since $1987 .{ }^{19}$ For each inpatient episode, information on discharge diagnoses (main and up to seven contributory diagnoses, coded according to the International Classification of Diseases $(\mathrm{ICD})^{21}$ ) are recorded, together with the national registration number (NRN), a 10 digit number unique to each Swedish resident and recorded in all health and census registers. ${ }^{22}$ In this register, we identified all hospital discharges including discharge dates listing GCA/PMR (temporal arteritis ICD7: 456.00 ICD8: 446.30 ICD9: 446F ICD10: M31.6; polymyalgia rheumatica ICD8: 446.38, ICD9: 725 ICD10: M31.5) among cases and controls, and among their spouses.

\section{Statistics}

The relative risk of malignant lymphoma associated with GCA/PMR was expressed as odds ratios (OR), derived from conditional logistic regression (to account for the matched design) using PROC PHREG in SAS ${ }^{\odot}$. Personal history of GCA was assessed for cases and controls up until one year before the diagnosis of lymphoma in the index case (in order to reduce bias from misdiagnosis and reversed causality), and stratified according to time between the first discharge listing GCA/PMR and lymphoma diagnosis (1-4, 5-9, 10+ years), age at first discharge listing GCA/PMR (50-74, 75+ years), age at lymphoma diagnosis (50-74, 75+ years), calendar period of GCA/PMR $(<1979,1980-1999)$, decade of lymphoma diagnosis (1965-1979, 1980-1989, 1990-1999), and sex. To evaluate the significance of environmental factors

Table 1 Number of cases with malignant lymphoma diagnosed in Sweden 1964-2000, and their matched controls

\begin{tabular}{|c|c|c|}
\hline & Cases & Controls \\
\hline Overall & 42676 & 78487 \\
\hline \multicolumn{3}{|l|}{ Sex } \\
\hline Male & 23994 & 44156 \\
\hline Female & 18682 & 34331 \\
\hline \multicolumn{3}{|l|}{ Age at lymphoma diagnosis } \\
\hline $50-74$ & 26363 & 48702 \\
\hline $75+$ & 16312 & 29783 \\
\hline \multicolumn{3}{|l|}{ Type of malignant lymphoma* } \\
\hline Hodgkin's lymphoma & 4037 & 7394 \\
\hline Non-Hodgkin's lymphoma & 28355 & 52164 \\
\hline Chronic lymphocytic leukaemia & 10555 & 19391 \\
\hline \multicolumn{3}{|l|}{ Year of lymphoma diagnosis } \\
\hline $1964-1979$ & 14147 & 26042 \\
\hline 1980-1989 & 13282 & 24722 \\
\hline $1990-2000$ & 15247 & 27723 \\
\hline Number of identified spouses & 31758 & 58458 \\
\hline
\end{tabular}

that could confound a statistical association between a personal history of GCA/PMR and lymphoma, we also calculated odds ratios for malignant lymphoma associated with having a spouse admitted to hospital with GCA/PMR.

\section{RESULTS}

Overall, 153 cases $(0.4 \%)$ and 345 controls $(0.4 \%)$ had been admitted to hospital with GCA/PMR one year of more before the lymphoma diagnosis in the index case, corresponding to a statistically significant $19 \%$ reduced risk $(\mathrm{OR}=0.81 \quad(95 \%$ confidence interval (CI), 0.67 to 0.98 ). The odds ratio varied little with time between the first discharge listing GCA/PMR and the lymphoma diagnosis $(0.79<\mathrm{OR}<0.87)$, calendar periods of GCA/PMR discharge $(0.78<\mathrm{OR}<0.88)$, age at GCA/ PMR (OR 50-74 years $=0.84$ (95\% CI, 0.65 to 1.08$)$; OR $75+$ years $=0.78$ (0.58 to 1.03$)$ ), age at lymphoma (OR 50-74 years $=0.95(0.67$ to 1.37$)$; OR $75+$ years $=0.76(0.60$ to 0.95$))$, and sex (ORs for males and females both $=0.81$ ). The numbers of discharges and the distributions of time between first GCA/ PMR discharge and lymphoma diagnosis were similar in cases and controls (data not shown). When stratified according to disease, the odds ratio for temporal arteritis ( $\mathrm{OR}=0.67$ (0.48 to 0.98)) appeared somewhat lower than that for polymyalgia rheumatica $(\mathrm{OR}=0.83(0.67$ to 1.04$))$. When the outcome was stratified according to lymphoma subtype, the odds ratios were essentially similar for NHL, HL, and CLL (table 2). In analyses from which all cases and controls who also had a registered discharge diagnosis of rheumatoid arthritis were excluded, the odds ratio remained similar $(\mathrm{OR}=0.82(0.67$ to 1.00$)$ ). Having a spouse admitted to hospital with GCA/PMR was neither associated with any altered lymphoma risk overall $(\mathrm{OR}=1.09$ (0.88 to 1.35$)$ ) nor with lymphoma type (table 2 ). The odds ratio for spouses' PMR (1.09) was similar to that of spouses' GCA (1.10).

\section{DISCUSSION}

Despite GCA/PMR being one of the most common rheumatic inflammatory diseases in the general population, and the fact that several other inflammatory diseases have been linked to increased lymphoma risk, the occurrence of cancer-including malignant lymphomas-following GCA/PMR has been little studied apart from the follow up of groups of patients too small $(n=50-400)$ to allow proper assessment of lymphoma risk. ${ }^{23-28}$ Our large, population based, nationwide case-control study resting on prospectively recorded data suggests that neither PMR nor GCA is associated with any increased short or long term occurrence of malignant lymphomas. Instead, we unexpectedly observed a moderate but statistically significantly $19 \%$ reduced lymphoma risk associated with GCA/PMR. Importantly, from a public health point of view, this unremarkable occurrence of lymphomas has wider implications. Because of the uniform and single treatment of GCA/PMR with steroids, our results imply that daily oral corticosteroids in moderate to high cumulative doses over one to three years do not increase the occurrence of malignant lymphomas.

Steroids have been implicated in lymphoma development in several recent moderate sized case-control studies of $\mathrm{NHL}^{1-4}$ (although exceptions exist ${ }^{56}$ ) and in a recently published cohort study from a prescription database. ${ }^{7}$ Inference on causality of the reported associations between steroids and lymphomas is, however, hampered by the lack of information on the underlying conditions necessitating treatment with steroids. Indeed, the chronic conditions (for example, rheumatoid arthritis, systemic lupus erythematosus, post-transplantation) that may lead to the highest cumulative doses of steroids are often-in themselves or through treatment with immunosuppressive drugs-associated with an increased occurrence of lymphomas. ${ }^{8-15}$ In 


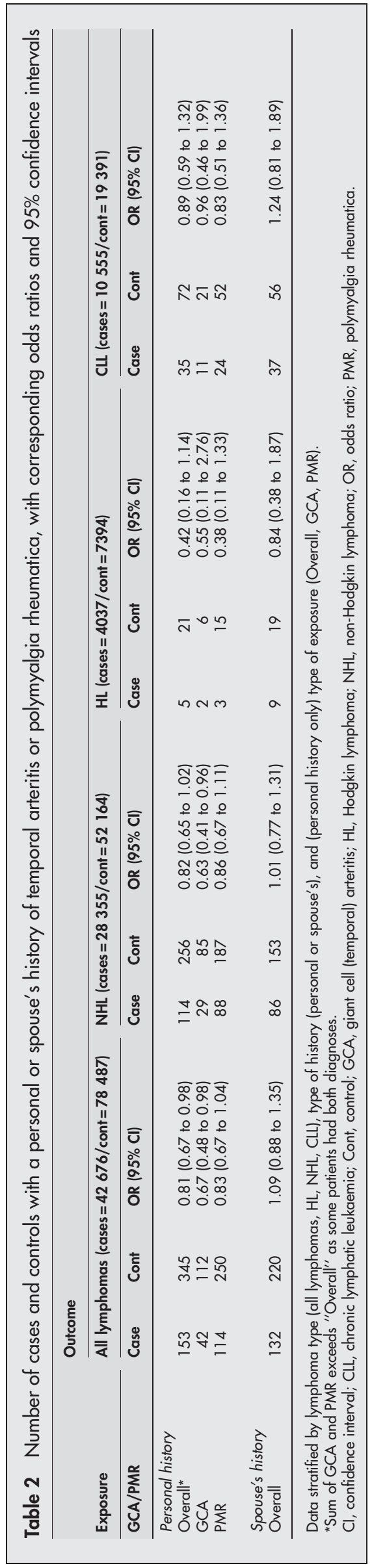

contrast, GCA/PMR can typically be brought into remission by steroids, and although relapses may occur during tapering of the steroids, GCA/PMR typically subsides after a few years of treatment with steroids as single therapy.

During the entire study period, oral steroids have represented the drug of choice in the treatment of GCA/PMR..$^{16}{ }^{17}$ Doses and duration of treatment may vary but add up to a minimum of one year of treatment/3 grams of prednisone, and often reach two years of treatment or more than 10 grams of prednisone, particularly during the decades covered by our study ( 1964 to 2000). Accordingly, although we lacked individual data on steroid exposure, few if any of our individuals with GCA/PMR may have been exposed to less than 3 grams of steroids. Our observation of a 20-30\% significant decrease in risk of malignant lymphomas in GCA/ PMR therefore strongly suggests that oral steroids do not increase lymphoma risk. One should not uncritically generalise our results to all settings in which steroids are used, including the partial suppression of inflammation in rheumatoid arthritis. The absence of risk increase associated with steroids in our study is, however, in line with findings from ongoing studies of rheumatoid arthritis, although in this group steroids have not been studied in the absence of disease modifying antirheumatic drugs and the underlying chronic rheumatoid disease. ${ }^{29}{ }^{30}$ Although we could not separate any effects of GCA/PMR from the effects of steroids, the proposed doubling of lymphoma risk associated with steroids ${ }^{7}$ would only be compatible with our odds ratio of 0.81 if untreated GCA/PMR by itself were somehow associated with a lymphoma risk that was reduced by two thirds or more, which must be considered highly unlikely. Only a small fraction of our patients with GCA/PMR (fewer than $10 \%$ ) will ever have received immunosuppressive treatment in addition to steroids, ${ }^{16}{ }^{18}$ but some may have used nonsteroidal anti-inflammatory drugs (NSAID) as symptom control. Most previous studies of NSAIDs have, however, either observed no risk increase ${ }^{13}$ or an increased lymphoma risk, ${ }^{2}{ }^{31}$ although there are exceptions. ${ }^{5}$ We therefore consider comedication unlikely to explain our results.

A particular strength of our study is its nationwide and population based setting, which provided the by far hitherto largest study population for the assessment of steroid associated lymphoma risks. The design allowed assessment of long term effects, changes in the association over calendar periods of GCA/ PMR or lymphoma diagnosis, and permitted risk assessments not only for NHL, but also for HL and CLL. Within the framework of our study, we did not have access to tissue specimens to validate the lymphoma diagnoses. Despite this, we consider misclassification of lymphomas to be low. In an ongoing case-control study of 378 lymphomas registered at the Cancer Register among patients with rheumatoid arthritis, only $2 \%$ of the registered lymphomas turned out to be incorrect upon validation. ${ }^{30}$ With respect to GCA/PMR, the overall diagnostic validity of the Swedish Inpatient Register is around $90 \%{ }^{19}$ Validations of the discharge diagnoses of, for example, rheumatoid arthritis and Wegener's granulomatosis indicate an overall validity close to $90 \%$ for these diagnoses as well. ${ }^{30} 3233$ We were unable to validate the diagnoses of GCA/PMR among cases and controls in our study. However, any misclassification of GCA/PMR is likely to affect cases and controls equally and would therefore result in a bias towards 1.0, and thus cannot explain our significantly reduced risks. To reduce the risk of reversed causality, we excluded GCA/PMR during the last year before lymphoma diagnosis. Inclusion of this year resulted in a virtually unchanged odds ratio for temporal arteritis and an odds ratio for polymyalgia rheumatica of 1.0 (data not shown).

The incomplete ascertainment of GCA/PMR (no information on GCA/PMR occurring before the start of the inpatient register in each county) applied equally to cases and controls, 
who were matched for geography, and does not in itself introduce measurable bias. Patients with symptoms suggestive of polymyalgia rheumatica may go on to develop rheumatoid arthritis. Whereas erroneous inclusion of such misdiagnosed rheumatoid arthritis might have biased our odds ratios, we observed almost no change in the odds in analyses from which cases and controls who also had a discharge listing of rheumatoid arthritis had been removed.

Our results apply to patients who had been admitted to hospital with GCA/PMR at some time. Although many patients with PMR/GCA are never admitted to hospital, we think it unlikely that the observed associations would be different in patients who were not admitted to hospital, as these would be likely to have less severe disease and to receive lower doses of steroids. In any case, the requirement for hospital admission applied equally to cases and controls.

In contrast to previous questionnaire based case-control studies, our design rules out recall bias. Although adjustment for confounding was difficult, few risk factors for GCA/PMR and malignant lymphomas are established. The matched design and analysis ensured adjustment for the effects of sex, age, marital status, area of residence, and calendar period. Some studies have described a cyclic onset of GCA/PMR, ${ }^{34} 35$ and an infectious aetiology has been proposed. ${ }^{36}$ To assess any possible effects of such environmental exposures or undefined lifestyle factors that may have confounded an individual association between GCA/PMR/steroids and lymphoma, we included assessments of the spouses' history of GCA/PMR, as spouses tend to share lifestyle and environmental exposures, only to find associations close to 1.0.

In conclusion, the results of our nationwide case-control study suggest that neither treated GCA/PMR nor the corticosteroids used as its treatment increases lymphoma risk.

\section{ACKNOWLEDGEMENTS}

Supported by Swedish Cancer Society grant No 4537-B02-O2XBB.

\section{Authors' affiliations \\ J Askling, A Ekbom, Clinical Epidemiology Unit, Department of Medicine at Karolinska University Hospital Solna/Karolinska Institutet, Stockholm, Sweden}

L Klareskog, Rheumatology Unit, Department of Medicine at Karolinska University Hospital Solna/Karolinska Institutet

M Bï̈rkholm, Division of Haematology, Karolinska University Hospital Solna/Karolinska Institutet

H Hialgrim, Department of Epidemiology Research, Statens Serum Institut, Copenhagen, Denmark

E Baecklund, Department of Rheumatology, Uppsala Akademiska Hospital, Uppsala, Sweden

\section{REFERENCES}

1 Cartwright RA, McKinney PA, O'Brien C, Richards ID, Roberts B, Lauder I, et al. Non-Hodgkin's lymphoma: case control epidemiological study in Yorkshire. Leuk Res 1988;12:81-8.

2 Bernstein L, Ross RK. Prior medication use and health history as risk factors for non-Hodgkin's lymphoma: preliminary results from a case-control study in Los Angeles County. Cancer Res 1992;52:5510-15s

3 Zhang Y, Holford TR, Leaderer B, Zahm SH, Boyle P, Morton LM, et al. Prior Medical Conditions and Medication use and Risk of non-Hodgkin lymphoma in Connecticut United States Women. Cancer Causes Control 2004; 15:419-28

4 Kato I, Koenig KL, Shore RE, Baptiste MS, Lillquist PP, Frizzera G, et al. Use of anti-inflammatory and non-narcotic analgesic drugs and risk of nonHodgkin's lymphoma (NHL) (United States). Cancer Causes Control 2002;13:965-74.

5 Holly EA, Bracci PM. Population-based study of non-Hodgkin lymphoma, histology, and medical history among human immunodeficiency virusnegative participants in San Francisco. Am J Epidemiol 2003;158:316-27.

6 Beiderbeck AB, Holly EA, Sturkenboom MC, Coebergh JW, Stricker BH, Leufkens HG. No increased risk of non-Hodgkin's lymphoma with steroids, estrogens and psychotropics (Netherlands). Cancer Causes Control 2003; 14:639-44
7 Sorensen HT, Mellemkjaer L, Nielsen GL, Baron JA, Olsen JH, Karagas MR. Skin cancers and non-hodgkin lymphoma among users of systemic glucocorticoids: a population-based cohort study. J Natl Cancer Inst 2004:96:709-11.

8 Ekstrom K, Hjalgrim H, Brandt L, Baecklund E, Klareskog L, Ekbom A, et al. Risk of malignant lymphomas in patients with rheumatoid arthritis and in their first-degree relatives. Arthritis Rheum 2003;48:963-70.

9 Biornadal L, Lofstrom B, Yin L, Lundberg IE, Ekbom A. Increased cancer incidence in a Swedish cohort of patients with systemic lupus erythematosus. Scand J Rheumatol 2002;31:66-71.

10 Birkeland SA, Storm HH, Lamm LU, Barlow L, Blohme I, Forsberg B, et al. Cancer risk after renal transplantation in the Nordic countries, 1964-1986. Int J Cancer, 1995:60:183-9.

11 Kamel OW, Weiss LM, van de Rijn M, Colby TV, Kingma DW, Jaffe ES. Hodgkin's disease and lymphoproliferations resembling Hodgkin's disease in patients receiving long-term low-dose methotrexate therapy. Am J Surg Pathol 1996;20:1279-87.

12 Baecklund E, Ekbom A, Sparen P, Feltelius N, Klareskog L. Disease activity and risk of lymphoma in patients with rheumatoid arthritis: nested case-control study. BMJ 1998;317:180-1

13 Kinlen $\mathrm{LJ}$. Incidence of cancer in rheumatoid arthritis and other disorders after immunosuppressive treatment. Am J Med 1985;78:44-9.

14 Hazleman BL. The comparative incidence of malignant disease in rheumatoid arthritics exposed to different treatment regimens. Ann Rheum Dis 1982:41(suppl 1):12-17.

15 Asten P, Barrett J, Symmons D. Risk of developing certain malignancies is related to duration of immunosuppressive drug exposure in patients with rheumatic diseases. J Rheumatol 1999;26:1705-14.

16 Weyand CM, Goronzy JJ. Giant-cell arteritis and polymyalgia rheumatica. Ann Intern Med 2003;139:505-15.

17 Behn AR, Perera T, Myles AB. Polymyalgia rheumatica and corticosteroids: how much for how long? Ann Rheum Dis 1983;42:374-8.

18 Nuenninghoff DM, Matteson EL. The role of disease-modifying antirheumatic drugs in the treatment of giant cell arteritis. Clin Exp Rheumatol 2003;21/6 suppl 32):S29-34.

19 Patientregistret 1987-1996 Kvalitet och innehall. Stockholm: Epidemiologiskt Centrum, Socialstyrelsen, 1998.

20 Mattsson B, Wallgren A. Completeness of the Swedish Cancer Register. Nonnotified cancer cases recorded on death certificates in 1978. Acta Radiol Oncol 1984;23:305-13.

21 World Health Organisation. International classification of diseases. Geneva: WHO, 1955.

22 Lunde AS, Lundeborg S, Lettenstrom GS, Thygesen L, Huebner J. The personnumber systems of Sweden, Norway, Denmark, and Israel. Vital Health Stat 2, 1980;2:1-59

23 Myklebust G, Wilsgaard T, Jacobsen BK, Gran JT. No increased frequency of malignant neoplasms in polymyalgia rheumatica and temporal arteritis. A prospective longitudinal study of 398 cases and matched population controls. $J$ Rheumatol 2002;29:2143-7.

24 Haga HJ, Eide GE, Brun J, Johansen A, Langmark F. Cancer in association with polymyalgia rheumatica and temporal arteritis. J Rheumatol 1993:20:1335-9.

25 Schaufelberger C, Bengtsson BA, Andersson R. Epidemiology and mortality in 220 patients with polymyalgia rheumatica. Br J Rheumatol 1995;34:261-4

26 Salvarani C, Macchioni PL, Tartoni PL, Rossi F, Baricchi R, Castri C, et al. Polymyalgia rheumatica and giant cell arteritis: a 5-year epidemiologic and clinical study in Reggio Emilia, Italy. Clin Exp Rheumatol 1987;5:205-15.

27 Matteson EL, Gold KN, Bloch DA, Hunder GG. Long-term survival of patients with giant cell arteritis in the American College of Rheumatology giant cell arteritis classification criteria cohort. Am J Med 1996;100:193-6.

28 Chuang TY, Hunder GG, Ilstrup DM, Kurland LT. Polymyalgia rheumatica: a 10-year epidemiologic and clinical study. Ann Intern Med 1982;97:672-80.

29 Wolfe F. Inflammatory activity, but not methotrexate or prednisone use predicts non-Hodgkin's lymphoma in rheumatoid arthritis. Arthritis \& Rheumatism 1998;41(suppl 9):188.

30 Baecklund E, Ekbom A, Feltelius N, lliadou A, Backlin C, Askling J, et al. Disease activity, but not DMARD use, increases the risk for malignant lymphoma in rheumatoid arthritis: a case-control study of 378 RA lymphoma patients. Ann Rheum Dis 2004;63(suppl 1):103.

31 Cerhan JR, Anderson KE, Janney CA, Vachon CM, Witzig TE, Habermann TM. Association of aspirin and other non-steroidal antiinflammatory drug use with incidence of non-Hodgkin lymphoma. Int $J$ Cancer 2003;106:784-8.

32 Knight A, Askling J, Ekbom A. Cancer incidence in a population-based cohort of patients with Wegener's granulomatosis. Int J Cancer 2002;100:82-5.

33 Biornadal L, Baecklund E, Yin L, Granath F, Klareskog L, Ekbom A. Decreasing mortality in patients with rheumatoid arthritis: results from a large population based cohort in Sweden, 1964-95. J Rheumatol 2002;29:906-12

34 Petursdottir V, Johansson H, Nordborg E, Nordborg C. The epidemiology of biopsy-positive giant cell arteritis: special reference to cyclic fluctuations. Rheumatology (Oxford) 1999;38:1208-12.

35 Salvarani C, Gabriel SE, O'Fallon WM, Hunder GG. The incidence of giant cell arteritis in Olmsted County, Minnesota: apparent fluctuations in a cyclic pattern. Ann Intern Med 1995; 123:192-4.

36 Duhaut P, Bosshard S, Dumontet C. Giant cell arteritis and polymyalgia rheumatica: role of viral infections. Clin Exp Rheumatol 2000;18/4 suppl 20):S22-3 